\title{
Aspectos Gerais da Doença do Coronavírus 2019 (COVID-19)
}

\section{General Aspects of Coronavirus Disease 2019 (COVID-19)}

\author{
Silkiane Machado Capeleto*a; Rosevani F. Góes; ; Igor Rian Bonelli de Oliveira ${ }^{\text {a }}$ Osvaldo Borges Pinto Júniora; \\ Cristhiane Almeida Leite da Silva ${ }^{a}$; Walkiria Shimoya-Bittencourt ${ }^{\mathrm{a}}$
}

aUniversidade de Cuiabá, Programa de Pós-Graduação Stricto Sensu em Ambiente e Saúde. MT, Brasil.

*E-mail: silk_machado@hotmail.com

\begin{abstract}
Resumo
O COVID-19 se tornou rapidamente um grave problema mundial e de saúde pública em função de sua alta transmissibilidade. Por se tratar de uma nova epidemia, ainda sem tratamento específico e vacina, com pesquisas em andamento e muitas informações crescentes sobre este novo vírus, este estudo tem como objetivo possibilitar reflexões acerca da Pandemia causada pelo Coronavírus, conhecer os aspectos da COVID-19, assim como as ações mitigadoras necessárias para interromper a cadeia de transmissão e controle da doença com vistas a sintetizar informações educativas para a população. Foram pesquisados estudos sobre o COVID-19 na Pubmed/Medline e Lilacs, utilizando os seguintes descritores: "COVID-19", "SARS-CoV-2", "2019nCoV", "Pandemia". Os estudos demonstraram que a origem do SARS-CoV-2, agente causador da COVID-19, ainda não está completamente esclarecida. O alto poder de propagação do vírus pode estar relacionado à forma de transmissão e capacidade de sobrevivência do vírus em ambiente externo. As pessoas mais acometidas pelo vírus apresentam, em sua maioria, idade acima de 60 anos, presença de comorbidades como hipertensão e diabetes. O diagnóstico é, basicamente, clínico e/ou associado ao exame molecular e sorológico. Ainda não há medicamento específico para o tratamento da COVID-19, no entanto, alguns parecem promissores e se encontram em fase de ensaios clínicos. A única medida de prevenção da propagação ainda ocorre pelo seguimento das rotinas de higienização das mãos, isolamento social e uso de máscaras, além do engajamento de todos como cidadãos e como sociedade com atitudes pró-sociais de cuidado e autocuidado.
\end{abstract}

Palavras-chave: Coronavírus. COVID-19. SARS-COV-2. 2019nCoV. Pandemia.

\begin{abstract}
COVID-19 has quickly become a major global and public health problem due to its high transmissibility. As this is a new epidemic still without specific treatment and vaccine, with ongoing research and increasing information on this new virus, this study aims to enable reflections on the pandemic caused by coronavirus, know the COVID-19 aspects as well as the mitigating actions necessary to interrupt the disease transmission and control chain in order to synthesize educational information for the population. Studies on COVID-19 in Pubmed/Medline and Lilacs were researched, using the following descriptors: "COVID-19", "SARS-Cov-2", "2019nCoV", "Pandemic". Studies have shown that the origin of SARS-Cov-2, the causative agent of COVID-19, is not yet fully understood. The high virus propagation power may be related to the form of transmission and ability to survive in the external environment. The majority of people most affected by the virus present age above 60 years, presence of comorbidities such as hypertension and diabetes. The diagnosis is basically clinical and/or associated with molecular and serological examination. There is still no specific drug for the COVID-19 treatment, however, some seem promising and are at the clinical trials stage. The only prevention propagation measure is still by following the routines of hand hygiene, social isolation and wearing masks, in addition to the engagement of everybody as citizens and as a society with pro-social care and self-care attitudes.
\end{abstract}

Keywords: Coronavirus. COVID-19. SARS-COV-2. 2019nCoV. Pandemic.

\section{Introdução}

Um surto de doença respiratória, definida como "Doença do Coronavírus 2019 (COVID-19), tem ameaçado a saúde global desde seu reconhecimento, em dezembro de 2019, e se disseminou rapidamente pela China e, em poucas semanas, atingiu outros países e territórios ao redor do Mundo. Este novo Coronavírus (SARS-CoV-2) é estruturalmente relacionado ao mesmo vírus causador da síndrome respiratória aguda grave (SARS) e síndrome respiratória do Oriente Médio (MERS), consideradas grande emergência de doenças por Coronavírus dos últimos anos (WHO, 2020a; WIT, 2016; VILELA, 2020; CRODA, et al., 2020; WHO, 2020d; RODRIGUEZMORALES, et al., 2020).
O vírus identificado como SARS-CoV, responsável por ocasionar uma pneumonia com risco de vida, sendo considerado o Coronavírus humano mais patogênico identificado até o momento, pressupondo-se que inicialmente resida em um reservatório animal (morcegos, pangolim e outros animais selvagens) iniciando a transmissão zoonótica da epidemia em humanos e, posteriormente, de pessoa para pessoa (LU et al., 2020; LAM et al., 2020; ZANG et al., 2020).

Nessa abordagem, as pesquisas apontam que os primeiros casos da doença COVID-19 se relacionaram ao mercado Huanan Seafood Market em Hubei, na China, no qual se comercializavam peixes, frutos do mar e até mesmo animais vivos (LI et al., 2020).

Em função do alto poder de infecção e disseminação do 
vírus acompanhados pelas altas taxas de notificações na China com proporções internacionais, o Comitê de Emergência da Organização Mundial de Saúde (OMS) declarou como sendo uma emergência de saúde global com base nas crescentes taxas de notificação de casos em locais chineses e internacionais (WHO, 2020).

A infecção ocorre por meio da inalação de gotículas geradas durante a tosse e espirro de pacientes sintomáticos e assintomáticos lançadas ao ar por 1-2 m, depositadas em superfícies contaminadas, com manuseio pelas mãos ao nariz, olhos e boca. O período de incubação varia de 2 a 14 dias, conforme as características epidemiológicas (OMS, 2020; ROTHE et al., 2020; KAMPF et al., 2020).

Estudos apontam que a incidência de infecção por SARSCoV-2 é observada com mais frequência em pacientes adultos do sexo masculino, com a idade média dos pacientes entre 34 e 59 anos, com maior probabilidade de acometer pessoas com a pré-existência de comorbidades crônicas, como doenças cardiovasculares e cerebrovasculares e diabetes. As crianças podem ter menos probabilidade de se contaminarem, em caso de possibilidade podem apresentar manifestações mais leves do que os adultos (HUANG et al., 2020; BAI et al., 2020; WANG et al., 2020; CHANG, et al., 2020).

Os sintomas comumente apresentados incluem: febre, tosse, mialgia e fadiga, podem também inicialmente apresentar diarreia e náusea alguns dias antes de desenvolver febre. Outras pessoas podem ter cefaleia ou hemoptise e/ou ser relativamente assintomáticos (GUAN et al., 2020; CHAN et al., 2020; WANG et al., 2020). Importante destacar que homens idosos com comorbidades são mais predispostos a desenvolverem insuficiência respiratória em função de dano alveolar grave (CHEN et al., 2020). A doença, em seu estágio inicial, pode mostrar rápida progressão para disfunção orgânica (por exemplo, choque, síndrome do desconforto respiratório agudo, lesão cardíaca aguda e lesão renal aguda) e até morte em casos graves (HUANG et al., 2020; WANG et al., 2020).

Por não existir tratamento antiviral específico para essa infecção, a aplicação da prevenção é crucial para o maneja da doença, isolamento e os cuidados de suporte, incluindo oxigenoterapia, gestão de fluidos e tratamento com antibióticos para infecções bacterianas secundárias são as viabilidades recomendadas até o momento (TANG et al., 2020; HABIBZADEH, STONEMANO, 2020).

Nesse contexto, considerando a complexidade e a importância dessa nova doença, assim como a relevância da situação epidemiológica, do enfrentamento atual e do risco potencial de introdução deste novo Coronavírus COVID-19, em vários países, justifica-se a realização deste estudo, no intuito de possibilitar reflexões acerca da Pandemia causada pelo Coronavírus, conhecer os aspectos gerais da COVID-19, assim como as ações mitigadoras necessárias para interromper a cadeia de transmissão e controle da doença com vistas a sintetizar informações educativas para a população.

\section{Desenvolvimento}

\subsection{Metodologia}

Foram utilizadas como fontes de informação a plataforma PubMED/MEDLINE e a base de dados Literatura Latinoamericana e do Caribe em Ciências da Saúde (LILACS), envolvendo o contexto sobre os aspectos gerais da doença do novo Coronavírus 2019 (COVID-19), causador da Pandemia mundial, a partir de dezembro de 2019 e o ano de 2020. Consideraram-se os seguintes descritores: "COVID-19", "SARS-CoV-2" e "2019nCoV”. Incluíram-se artigos nos idiomas inglês e português publicados em periódicos nacionais e internacionais acerca da temática de pesquisa. Excluíram-se os estudos com modelo animal. Em seguida, os dados foram organizados nas seguintes categorias temáticas: Histórico e Contextualização da Pandemia Mundial pela Doença de Coronavírus 2019 (COVID-19); Os impactos gerados pela Pandemia na vida das pessoas, na economia, no meio ambiente e na saúde, as Características Gerais do Novo Coronavírus 2019 (COVID-19) e Medidas não farmacológicas e Prevenção do COVID-19.

\subsubsection{Histórico e Contextualização da Pandemia Mundial pela Doença de Coronavírus 2019 (COVID-19)}

O conhecimento sobre a existência do novo Coronavírus ocorreu em dezembro de 2019, quando a OMS foi informada sobre a presença de diversos casos pouco habituais de pneumonia em Wuhan, capital da Província de Hubei, na China (VILELA, 2020; CRODA et al., 2020). Logo no princípio de ano de 2020, houve a identificação e confirmação de um novo Coronavírus (SARS-CoV-2), pertencente a mesma família ocasionadora das epidemias de SARS (Severe Acute Respiratory Syndrome) e de MERS (Middle East Respiratory Syndrome) (RODRIGUEZ-MORALES et al., 2020; WHO, 2020b).

A OMS emitiu notas com orientações gerais sobre medidas de prevenção e tratamento, conforme as realizadas para prevenção da infecção pelo vírus influenza, causador da gripe. Com a ocorrência de um óbito decorrente do agravamento do quadro clínico de pneumonia, iniciaram-se inúmeras investigações para elucidar essa nova doença. A partir de então se identificou o agente etiológico como Coronavirus disease 2019 (COVID-19) e foram divulgados alertas e recomendações pelas entidades de saúde, especialmente, para viajantes provenientes de Wuhan, que tivessem sintomas respiratórios, que deveriam contar a seus médicos sobre a viagem e possível contaminação (HENRIQUE; VASCONCELOS, 2020).

Pesquisas apontam que, até dezembro de 2019, essa doença não havia afetado indivíduos de nossa espécie, fato este que permite induzir que se inclui a possibilidade de uma rara proteção natural, a população mundial seja integralmente suscetível ao contágio, pois nenhuma pessoa antes teve contato 
com o vírus Sars-CoV-2 (HENRIQUE; VASCONCELOS, 2020).

A nova doença, denominada de COVID-19, se disseminou pela China atingindo rapidamente outros países da Ásia, se espalhando em todos os Continentes e, praticamente, todos os países, considerado a terceira ameaça global à saúde pública, após o SARS e o MERS (NASSIRI, 2020; RODRIGUEZMORALES et al., 2020; HENRIQUE; VASCONCELOS, 2020).

No Continente americano, o primeiro caso reportado, em 21 de janeiro de 2020, ocorreu nos Estados Unidos da América, por meio de uma pessoa que havia viajado à Wuhan. Ao final desse mesmo mês, no Japão, Tailândia, Coreia do Sul e Europa (Espanha, França e Itália) também registraram os primeiros casos (STORYMAPS, 2020). Na América Latina, o primeiro caso confirmado ocorreu no Brasil no dia 26 de fevereiro, e após poucos dias foi reportado o primeiro caso na Argentina. Em ambos os casos, as pessoas haviam viajado à Itália (VILELA, 2020; RODRIGUEZ-MORALES et al., 2020; HOPKINS, 2020).

A COVID-19 mobilizou a comunidade de cientistas, que incansavelmente, trabalha para entendê-la e curá-la, desenvolvendo importantes ações em todo o Mundo em busca de soluções. A disseminação da doença trouxe à tona as fragilidades até então desconhecidas de diversos setores, demonstrando a necessidade de mudanças nos sistemas sanitário e de saúde, a carência de profissionais de saúde e a importância do investimento na ciência (RIBOLI et al., 2020).

Mesmo com a realização de diversos estudos, pesquisas e testes, ainda não há disponível medicamento ou vacina antivírus oficialmente aprovado e liberado pelas autoridades de saúde para tratar o COVID-19, embora muitos países estejam trabalhando exaustivamente para tal. Atualmente, o manejo clínico inclui prevenção de infecções, medidas de controle e cuidados de suporte, incluindo oxigênio suplementar e ventilação mecânica, quando indicado. $\mathrm{O}$ principal tratamento até agora para esse vírus é o uso de antivirais, que enfraquecem a capacidade dos vírus de entrar nas células e impedem que se multipliquem ou se movam de células infectadas para outras. Os antibióticos não têm função no tratamento de pacientes com COVID-19, mas podem ser usados no caso de uma infecção bacteriana secundária (ABD EL-AZIZ; STOCKAND, 2020).

Com a apresentação do cenário causado pela Pandemia, a OMS buscou alternativas na tentativa de conter ou frear a disseminação do vírus, entre essas a realização do distanciamento social e medidas de saúde pública (WHO, 2020). Nessa perspectiva, vários países interromperam aulas, atividades comerciais, cancelamento e proibições de eventos sociais, culturais e esportivos, além da redução da frota dos veículos de transporte, fechamentos de aeroportos e terminais de trens e ônibus de forma a restringir a circulação de pessoas, permanecendo apenas as essenciais como supermercados e farmácias (EBRAHIM et al., 2020).
De forma geral, as medidas adotadas pelos países foram sendo aplicadas, conforme as recomendações das autoridades de saúde e esferas governamentais, com duração e dimensões diferentes no intuito de evitar ou diminuir a taxa e velocidade de disseminação e contágio do vírus. Nesta nova e necessária configuração, a população passou a exercer hábitos de distanciamento social, lockdown, medidas rotineiras de higiene pessoal (lavagem frequente das mãos, utilização de álcool gel a $70^{\circ}$ e máscaras), isolamento social, restrição de circulação e aglomeração de pessoas, quarentena para pessoas que tiveram contato com um paciente contaminado, ou na espera de diagnóstico ou que pertencem a grupos de risco (EBRAHIM et al., 2020).

A fim de minimizar a propagação do SARS-CoV-2, a China bloqueou Wuhan e cidades próximas desde 23 de janeiro de 2020. As medidas de controle sem precedentes, incluindo a suspensão de todo o transporte urbano, aparentemente tiveram sucesso na prevenção da propagação do SARS-CoV- 2 para outras cidades (WU et al., 2020).

No Brasil, em meados do mês de março de 2020, as diversas autoridades, do Poder Executivo (Federal, Estadual e Municipal), iniciaram a exarar medidas normativas progressivas e, rapidamente, mais restritivas de liberdade de locomoção da população civil. Lockdown nas cidades, barreiras físicas, e até impedimento de acesso às cidades e aos Estados foram intentadas para conter o avanço do COVID- 19 (GONÇALVES, 2020).

A efetividade das medidas adotadas por Estados e municípios para a relação ao bloqueio, está relacionada com a população em aceitar e aderir ou não a essas. Os países e localidades, nos quais houve aceitação e cumprimento, se saíram melhor. Em questão, o Brasil, se apresenta como um país extremamente desigual, expressando uma tendência de grandes desigualdades da distribuição de renda e elevados níveis de pobreza, de grandes injustiças sociais, que exclui parte significativa de sua população do acesso às condições mínimas de dignidade e cidadania (BARROS et al., 2000).

Outra questão importante diante as medidas adotadas decorre por parte da população, que tende a minimizar a amplitude e gravidade da Pandemia, essa postura ocorrem em função de dificuldades de comunicação da Ciência e da academia com o conjunto da sociedade e negação ou desvalorização da Ciência e do conhecimento científico (PIVA, 2020).

A Organização Pan-Americana da Saúde/Organização Mundial da Saúde tem alertado para que Estados Membros mantenham os serviços de saúde preparados para enfrentarem ondas e surtos recorrentes em diferentes locais dentro do mesmo país, simultaneamente ou em diferentes momentos, à medida que a economia seja retomada progressivamente. Ressalta, ainda, o empenho para a garantia ao acesso de toda a população a testes diagnósticos e atendimento adequado aos pacientes em todos os níveis de atenção à saúde (WHO/ PAHO, 2020e). 
O controle e monitoramento dos padrões de caso de COVID-19, pelos Estados membros, se faz necessário para que a partir da caracterização de cada faixa etária na dinâmica de transmissão do SARS-CoV-2, as estruturas de apoio e resposta possam garantir também a ação rápida dos serviços de saúde diante de novos aumentos nos casos (WHO/PAHO, 2020e)

\subsubsection{Os impactos gerados pela Pandemia na vida das pessoas, na economia, no meio ambiente e na saúde}

Diante do cenário resultante da Pandemia, além do agravamento das taxas de morbidade e mortalidade, muitas mudanças ocorreram na vida da população e na dinâmica das cidades, de forma drástica, causando graves prejuízos, danos e crises na economia, na saúde, meio ambiente e, também, no comportamento e nas relações sociais.

Desde o surgimento do vírus, em dezembro de 2019, na cidade de Wuhan, na China, o Mundo tem vivenciado situações atípicas, marcada pela Pandemia do novo coronavírus. Em função do seu alto potencial de contágio, a OMS junto a diversos e renomados centros de pesquisa do Mundo, recomendaram que as pessoas permanecessem em casa, modificando a vida da humanidade (OMS, 2020a; THOMPSON, 2020; BEZERRA, et. al., 2020). Por ser considerado o método mais eficaz no combate à disseminação da nova Pandemia, a COVID-19, em poucas semanas de isolamento social passou de uma medida local para uma medida Internacional (WHO, 2020f).

Em função da rápida disseminação do vírus pelo Planeta, a Pandemia tem transformado drasticamente as relações interpessoais para um novo status: online e offline, mesmo que anteriormente à chegada da Pandemia, o mundo digital já fazia parte da vida em sociedade, porém pelo momento atípico, a situação não proporciona tanto conforto como antes. Além disso, a sociedade se encontra refém deste novo status e da insegurança do controle da situação (PONDÉ, 2020).

De forma global, estruturas econômicas foram estremecidas pela ocorrência da Pandemia do novo coronavírus (SARS-CoV-2), sobretudo, nos países designados como subdesenvolvidos ou emergentes. Contudo, em decorrência do grande impacto provocado pela COVID-19, até mesmo os países mais organizados, financeiramente, tiveram suas economias abaladas (SILVA et al., 2020).

Nesse contexto, os autores Silva et al. (2020) trazem, em seu artigo, uma importante inferência sobre o impacto da crise econômica decorrente da COVID-19 feita pela professora Rosa Maria Marques do Departamento de Economia da PUC/ SP, a qual aponta a situação avassaladora para os países que não fazem parte do seleto grupo dos desenvolvidos, que em função da globalização e da organização da economia mundial em rede, até mesmo os lugares não afetados pelo vírus sofreram consequências, uma vez que a Pandemia obrigou a paralização de atividades que injetam recursos em todos os setores econômicos, ocasionando uma queda exponencial no setor de empego e renda.

O fenômeno causado pela repercussão do novo Coronavírus no mercado financeiro mundial aconteceu, de forma assimétrica, podendo ser explicado pela natureza trans escalar (diz respeito à forma como o Mundo inteiro foi afetado pelo surto da COVID-19, gerando impactos negativos no mercado financeiro, na produção e no consumo ) e intertemporal (mediante os efeitos provocados pelo vírus em curto, médio e longo prazo afetando, sobretudo, o abastecimento de microeconomias, as cadeias de produção e a aceleração de macroeconomias internacionais) (SENHORAS, 2020).

O dano financeiro, causado pela quarentena, além de ser um problema socioeconômico sério, é considerado mais um fator de risco para os sintomas e agravos de distúrbios psicológicos, podendo permanecer por vários meses após a quarentena. Mesmo com a existência das medidas de apoio do Governo, o quantitativo recebido se torna insuficiente para a aquisição de suprimentos básicos (comida, água, roupas ou acomodação), que conforme estudos já realizados, esse fator era a principal fonte de frustração das pessoas e associado à ansiedade e à raiva por diversos meses, após o fim do isolamento (LIU et al., 2012; BLENDON et al., 2004; WILKEN et al., 2017).

Com a rápida disseminação da doença, vários foram os desafios e as preocupações das autoridades de saúde em âmbito global, aos quais se relacionam com o acesso aos exames diagnósticos, a identificação dos casos, testagem dos casos suspeitos para o controle da Pandemia, os testes em massa e as falhas no sistema de vigilância em saúde, resultando em subnotificação, principalmente, nos países de baixa e média renda (TURCI et al., 2020; DE OLIVEIRA et al., 2020; BEECHING et al., 2020; OMS, 2020; ROCHA, 2020).

Ademais, muitos países se viram diante do despreparo e o colapso dos sistemas de saúde, em função do alto número de internações nos hospitais, falta de leitos e recursos materiais para o atendimento ao paciente, como: medicamentos, equipamento de proteção individual, respiradores, além do esgotamento psicológico e físico dos trabalhadores da área de saúde (REQUIA et al., 2020), que agravado pela contaminação de muitos deles, pode levar, como já advertido pela OMS, a que outras enfermidades evitáveis sejam negligenciadas (WHO, 2020c).

\subsubsection{Características Gerais do Novo Coronavírus 2019 (COVID-19)}

A COVID-19 é uma doença ocasionada pelo vírus denominado SARS-CoV-2. Este vírus pertence ao gênero betaCovs, da subfamília Orthocoronavirinae, da família Coronaviridae. Trata-se de um vírus envelopado, ou seja, possui uma membrana lipídica dupla com proteínas, de fita única de RNA, possuindo a forma de coroa, por conta das glicoproteínas em forma de espinhos, presentes em seu envelope, denominando-o de Coronavírus (BRASIL, 2020a; 
WHO, 2020a; MCINTOSH, 2020; CASCELLA et al., 2020; VELAVAN et al., 2020).

Em função da formação morfológica do vírus, sua aparência ocorre devido ao pico "S" da glicoproteína, que irradia do vírus de superfície viral e a glicoproteína transmembrana "M", estas consideradas as duas principais do envelope (E). A glicoproteína S é um antígeno, que se liga ao receptor, sendo responsável pela fusão celular, já a glicoproteína $\mathrm{M}$ tem um papel importante na formação do envelope e na montagem do vírion (JACOFSKY et al., 2020; UJIKE, TAGUCHI, 2015).

Quanto ao genoma de RNA, compõe-se de fita simples positivo com cerca de 26-32 Kbp (quilobases) de tamanho, considerado o maior RNA genômico conhecido entre os vírus, contendo de 7-10 diferentes quadros de leitura aberta (COMAS-GARCIA, 2019; MOUSAVIZADEH, GHASEMI, 2020; WEISS, NAVAS-MARTIN, 2005).

Os Coronavírus possuem quatro subfamílias: alfa, beta, gama e delta. Os Coronavírus alfa e beta se originam de mamíferos, enquanto os Coronavírus gama e delta foram identificados em porcos e aves. Os beta-coronavírus também se denominam de Coronavírus de morcego, tal fato se aplica pelos $90 \%$ de semelhança da sequência de RNA de 2019nCoV a um Coronavírus de morcego RaTG13 (VELAVAN et al., 2020; LI et al., 2020). Apresenta-se fortemente conexo à linhagem $\mathrm{B}$ dos beta-coronavírus, frequentemente conhecidos por ocasionarem doenças graves e fatais (LETKO; MUNSTER, 2020), enquanto os alfa-coronavírus causam doença assintomática ou levemente sintomática (VELAVAN et al., 2020; LI et al., 2020).

Segundo pesquisadores, o genoma completo do vírus foi sequenciado e, também, depositado em um banco de dados gnômico, para que posteriormente sejam estudados a determinação da sequência de aminoácidos e a estrutura das proteínas 2019-nCoV e, também como prever suas interações com as células hospedeiras (BELOUZARD et al., 2012).

A transmissão da doença ocorre através de gotículas ou contato direto, e se estima que a infecção tenha um período médio de incubação de 6,4 dias e uma transmissibilidade (RO) que varia de 2,24 a 3,58 (LAI et al., 2020). Segundo informações divulgadas pelo Ministério da Saúde (BRASIL, 2020a), a transmissibilidade dos pacientes infectados por SARSCoV ocorre em média de 7 dias após o início dos sintomas. No entanto, dados preliminares de estudos sobre o novo Coronavírus (2019- nCoV) sugerem que a transmissão possa ocorrer mesmo sem o aparecimento de sinais e sintomas. Até o momento, não há informação suficiente de quantos dias anteriores ao início dos sinais e sintomas uma pessoa infectada passa a transmitir o vírus.

O período de incubação varia entre 1 a 14 dias e os doentes podem ser assintomáticos e transmitir a doença. Os sintomas são inespecíficos, ocorrendo frequentemente a febre, a tosse, a dispneia, as mialgias e fadiga (LAI et al., 2020). Esses sintomas podem variar desde um resfriado, a uma Síndrome
Gripal-SG e até uma pneumonia severa. Além dos sintomas já mencionados, podem ocorrer ainda coriza, dor de garganta, dificuldades para respirar, perda de olfato (anosmia), alteração do paladar (ageusia), distúrbios gastrointestinais (náuseas/ vômitos/diarreia), cansaço (astenia), além da diminuição do apetite (hiporexia) (BRASIL, 2020a).

Autores descrevem que o diagnóstico clínico de COVID-19 se baseia nas manifestações clínicas, diagnóstico molecular do genoma viral por reação em cadeia da polimerase de transcrição reversa em tempo real (RT-PCR), raio-x ou tomografia computadorizada de tórax e exames de sorologia de sangue. Ainda, apresentam como alterações laboratoriais de pacientes com RT-PCR positivo: a linfopenia, leucopenia, trombocitopenia, PCR elevada e marcadores inflamatórios, biomarcadores cardíacos elevados, albumina diminuída e função renal e hepática anormais (PARANJPE et al., 2020; ZHU et al., 2020).

Atualmente, não há medicamentos específicos registrados para o tratamento da doença COVID-19, assim como uma vacina ainda não está disponível. O manejo do quadro clínico se baseia, principalmente, na terapia de suporte e no tratamento dos sintomas e na tentativa de prevenção da insuficiência respiratória (PROMPETCHARA et al., 2020; PANG et al., 2020; SHANMUGARAJ et al., 2020).

Independentemente do quadro apresentado pelo paciente, garantir o isolamento do paciente para evitar a transmissão a outros pacientes, familiares e profissionais de saúde é de fundamental importância. Devem ser tomadas medidas de quarentena para isolar indivíduos infectados, tanto sintomáticos como assintomáticos, e qualquer pessoa que possa ter estado em contato com eles. Populações inteiras devem limitar o contato social e minimizar o tempo passado fora (BROOKS et al., 2020; PARMET et al., 2020).

Em pacientes com casos leves, o ideal é que se faça o autoisolamento em casa, mantendo hidratação e nutrição adequadas e tratando os sintomas comuns. Tal atitude contribui para que os leitos hospitalares estejam disponíveis para receberem os casos graves (SINGHAL et al., 2020).

Conforme exposto, as informações obtidas quanto à disponibilidade farmacológica para o tratamento da COVID-19 partem dos medicamentos utilizados durante as Pandemias anteriores de SARS-CoV ou MERS-CoV ou de observações in vitro (ASHOUR et al., 2020; YANG et al., 2020). Nessa conjuntura, diversos ensaios clínicos utilizando como base as drogas antivirais, anti-inflamatórias e imunomoduladoras, terapia celular, antioxidantes e outras terapias estão sendo realizados, em busca de possíveis tratamentos para COVID-19 (ZANG et al., 2019).

Pesquisas, que buscam o desenvolvimento de drogas para o tratamento da 2019-nCoV, têm se concentrado em imunomoduladores, produção de anticorpos monoclonais e agentes inibitórios contra proteinase viral, helicase e polimerases, porém ainda não há aprovações de nenhum 
tratamento antiviral ou vacina específica para COVID-19 (PERALES et al., 2016; PRUIJSSERS; DENISON, 2019; LU, 2020).

O quadro clínico da doença apresentado pelo paciente é controlado, especificamente, com base nos sintomas e por meio dos medicamentos terapêuticos disponíveis, já em casos mais graves, o controle ocorre por meio de cuidados de suporte vital, incluindo oxigênio e ventilação mecânica (HE et al., 2020).

Terapeuticamente são utilizados para o tratamento de pacientes com COVID-19 os agentes antivirais (Remdesivir, Cloroquina, Tocilizumabe, Hidroxicloroquina, Umifenovir, Lopinavir, Oseltamivir e Favipiravir) e os agentes adjuvantes (zinco, vitamina D, Azitromicina, Ácido ascórbico óxido, corticosteroides, antagonistas de IL-6). Nesse contexto, tendo em vista que a carga viral atinge seu pico próximo ao início dos sintomas, os medicamentos antivirais, juntamente com agentes adjuvantes, utilizados de forma combinada, podem suprimir rapidamente o número de vírus no corpo de um paciente, e agir de forma positiva na redução da gravidade da doença e duração da infecção viral (HE et al., 2020).

Sobre os agentes antivirais Cloroquina e a Hidroxicloroquina, esses foram utilizados há mais de anos como tratamento antimalária, antiamebiose e anti-vírus da imunodeficiência humana. Estes, além de demonstrarem eficiência, no tratamento contra a infecção por SARS-CoV e prevenir a propagação do vírus, podem aumentar o risco de problemas cardíacos (arritmias cardíacas e parada cardíaca) em pacientes com COVID-19 (SINGH et al., 2020).

Além dos agentes químicos, foram sugeridos para o tratamento do COVID-19 os medicamentos fitoterápicos tradicionais e plasma convalescente, tendo em vista que a OMS acredita que a medicina tradicional, complementar e alternativa apresenta muitos benefícios. Nessa perspectiva, alguns países como o Irã, a China, a Índia, a Coreia e partes da África, já vivenciam a medicina tradicional e sugeriram diretrizes médicas para o tratamento de COVID-19.

\subsubsection{Medidas não farmacológicas e Prevenção do COVID-19}

Em função do alto poder de propagação da COVID-19, essa se tornou rapidamente uma Pandemia. Sua elevada infectividade, aliada à ausência de imunidade prévia na população humana e à inexistência de vacina, fez com que o crescimento do número de casos aumentasse rapidamente, sendo necessária a adoção de medidas para conter sua transmissão (KUCHARSKI et al., 2020).

Os principais estudos realizados relatam que o SARSCoV-2 pode se espalhar mais facilmente e causar doenças com risco de vida em comparação com outros vírus $\mathrm{CoV}$ (VAN DOREMALEN et al., 2020), sendo transmitido por meio de transmissão animal-humano e transmissão humanohumano, através de gotículas ou contato direto, alguns estudos mostraram que o 2019-nCoV é sensível à luz ultravioleta e ao calor como outros CoVs. Neste sentido, para prevenir a propagação do vírus se aplica a utilização de diferentes solventes como etanol (70\%), éter (75\%), desinfetantes contendo cloro e outros, que podem inativar sua funcionalidade (LI et al., 2020).

Os autores Rabenau et al. (2005) corroboram com o exposto, acrescentando ainda sobre a eficácia dos desinfetantes contra vírus com envelope, assim como o 2019-nCoV, que possivelmente é suscetível a desinfetantes, incluindo ainda alvejante (hipoclorito de sódio), peróxido de hidrogênio 0,5\%, compostos de amônio quaternário e compostos fenólicos, desde que utilizados, conforme as recomendações do fabricante. Acrescentam, ainda, que agentes biocidas, como 0,05- $0,2 \%$ de cloreto de benzalcônio ou $0,02 \%$ de digluconato de clorexidina podem ser menos eficazes (WHO, 2014). Nesse contexto, por ainda não haver nenhuma vacina aprovada e seu desenvolvimento requerer um determinado prazo, é de grande importância seguir as recomendações sobre o isolamento e/ou afastamento social, além da lavagem das mãos e desinfecção de suas casas e locais de trabalho.

Estudos e relatórios de saúde também mostram que o SARS-CoV-2, como outros Coronavírus, pode sobreviver no ar por até $3 \mathrm{~h}$ e pode permanecer em plástico por $72 \mathrm{~h}, 48 \mathrm{~h}$ em aço inoxidável, $24 \mathrm{~h}$ em papelão e $4 \mathrm{~h}$ em cobre. No entanto, multiplica-se velozmente no corpo, mesmo quando uma pessoa infectada seja assintomática, podendo ser transmitido a outra (VAN DOREMALEN et al., 2020).

Nesse contexto, são indicadas intervenções não farmacológicas (INF), que incluem medidas com alcance individual, ambiental e comunitário, como a lavagem das mãos, a etiqueta respiratória, o distanciamento social, o arejamento e a exposição solar de ambientes, a limpeza de objetos e superfícies, e a restrição ou proibição ao funcionamento de escolas, universidades, locais de convívio comunitário, transporte público, além de outros locais nos quais haja aglomeração de pessoas (GARCIA; DUARTE, 2020).

Por se tratar de infecção respiratória há evidências de que as intervenções não farmacológicas são métodos efetivos para a redução da morbidade e mortalidade, desde que, quando utilizada, para limitar a transmissão de doenças, requer a aplicação e introdução de diversas estratégias ao longo da Pandemia, dependendo da gravidade da situação e dos padrões de transmissão local. E quando usadas em combinação, essas intervenções podem agir de forma complementar, ou mesmo sinérgica, de modo a restringir, gradativamente, a transmissão (QUALLS et al., 2020).

De um modo geral, cada país adotou suas medidas para a contenção da disseminação do vírus. A China, rigorosamente e ágil, adotou diversas medidas e intervenções, como: determinações para distanciamento social, fechamento de estabelecimentos, bloqueio da cidade, quarentena em massa e busca de casos e contatos. Em tempo, a China utilizou, também, uma importante estratégia complementar no 
enfrentamento à COVID-19, trata-se da utilização massiva de máscaras por toda a população, inclusive, as assintomáticas (WHO, 2020; LEUNG, 2020).

Corroborando com o exposto, a OMS e demais organizações publicaram algumas diretrizes básicas para prevenir o COVID-19, conforme apresentado por Jin et al. (2020) e Wang et al. (2020c), tais como: lavar as mãos com frequência e cuidado, especialmente, após o contato com pessoas infectadas ou seu ambiente; evitar tocar no próprio rosto, incluindo boca, nariz e olhos; cobrir boca e o nariz ao tossir e espirrar; levar a sério o distanciamento social, mantendo uma distância considerável de dois metros de outras pessoas e se manter em quarentena se estiver doente e usar uma máscara quando precisar de cuidados médicos.

Com o mesmo teor de prevenção, a OMS divulgou, também, orientações referentes às orientações de biossegurança laboratorial relacionadas ao nCoV 2019, em que se torna obrigatória a utilização de máscaras FFP3 ou N95 e outros equipamentos de proteção pelos profissionais de saúde e pesquisadores, ao contato e proximidade de pacientes COVID-19 (WANG et al., 2020).

Todas as medidas adotadas desde o início de um período epidêmico auxiliam, tanto na prevenção da transmissão quanto na diminuição da velocidade de propagação da doença, contribuindo para o achatamento da curva epidêmica. Assim, é possível diminuir a demanda instantânea por cuidados de saúde e mitigar as consequências da doença sobre a saúde das populações, incluindo a redução da morbidade e da mortalidade associadas (QUALLS et. al., 2020)

Todavia, ainda se faz necessário seguir, corretamente e rigorosamente, as rotinas de higienização das mãos, isolamento social e uso de máscaras sempre que sair à rua, dedicar a viver o presente, sabendo que esta situação somente irá melhorar se houver o engajamento que a Pandemia exige de cada um como cidadão e que como sociedade se tenham atitudes pró-sociais de cuidado e autocuidado (LEDO, 2020).

\section{Conclusão}

Diante todo o contexto apresentado neste estudo, é possível perceber que a Pandemia da doença causada pelo novo Coronavírus 2019 (COVID-19) se tornou um dos grandes desafios do século XXI, tendo em vista que essa acomete inúmeros países e territórios em âmbito mundial. Os impactos causados pela Pandemia, ainda são inestimáveis, afetando direta e/ou indiretamente diversos setores, principalmente, a saúde da população, a economia e o ambiente.

Muitos avanços relacionados a esse patógeno foram alcançados através do árduo trabalho dos pesquisadores e autoridades da saúde, no intuito de conhecer os mecanismos de infecção, as características clínicas, interrupção da transmissão e prevenção da doença. Porém, em função do alto poder de transmissão, todos os países ao redor do Mundo devem aumentar a atenção para os sistemas de vigilância de doenças e intensificar as ações de prontidão dos países frente às operações de resposta, incluindo estratégias e plano assistencial de qualidade.

Nesse sentido, por ainda não ter medicamento específico para o tratamento da COVID-19 há, no entanto, alguns que parecem promissores e se encontram em fase de ensaios clínicos. Além disso, a única medida com alto poder de prevenção da propagação ainda ocorre pelo seguimento das rotinas de higienização das mãos, isolamento social e uso de máscaras, além do engajamento de todos os cidadãos e como sociedade com atitudes pró-sociais de cuidado e autocuidado.

\section{Referências}

ABD El-AZIZ, T. M.; STOCKAND, J. D. Recent progress and challenges in drug development against COVID-19 coronavirus (SARSCoV-2) - an update on the status. Infect Genet Evol., v.83, p.104327, 2020. doi: 10.1016/j.meegid.2020.104327.

PIVA, F. Negação da ciência cresce no Brasil e é uma ameaça em tempos de pandemia. ADUNICAMP. 2020. Disponível em: http://adunicamp.org.br/novosite/negacao-da-ciencia-cresce-nobrasil-e-e-umaameaca-em-tempos-de-pandemia/. Acesso em: 22 out. 2020 .

ASHOUR, H.M. et al. Insights into the Recent 2019 Novel Coronavirus (SARS-CoV-2) in light of past human coronavirus outbreaks. Pathogens., v.9, n.3, p.186, 2020. doi: 10.3390/ pathogens 9030186.

BAI, Y. et al. Presumed asymptomatic carrier transmission of COVID-19. JAMA, v.323, n.14, p.1406-1407, 2020. doi: 10.1001 / jama.2020.2565.

BARROS, et al. Desigualdade e pobreza no Brasil: retrato de uma estabilidade inaceitável. Rev. Bras. Cienc. Soc., v.15, n.42, p.123-142, 2000. doi: 10.1590/S0102-69092000000100009.

BEECHING. N.J. et al. Covid-19: test times. BMJ. v.369, p.403, 2020. doi: 10.1136/bmj.m1403.

BEZERRA, A. et al. Fatores associados ao comportamento da população durante o isolamento social na pandemia de COVID-19. Ciênc. Saúde Coletiva, v. 5, p.2411-2421, 2020. doi: 0.1590/1413-81232020256.1.10792020.

BELOUZARD, et al. Mechanisms of Coronavirus cell entry mediated by the viral spike protein. Viruses., v.4, n.6, p: 10111033, 2012. doi: 10.1086/382355.

BLENDON, R.J. et al. The public's response to severe acute respiratory syndrome in Toronto and the United States. Clin. Infect. Dis., v.38, n.7, p.925-931, 2004. doi: 10.1086/382355.

BRASIL. Ministério da Saúde. Secretaria de Atenção Primária à Saúde. Protocolo de Manejo Clínico do Coronavírus (COVID-19) na Atenção Primária à Saúde. Brasília: MS, 2020a.

BRASIL. Ministério da Saúde. Centro de Operações de Emergência em Saúde Pública. Brasília: MS, 2020.

BROOKS, S.K. et. al. The psychological impact of quarantine and how to reduce it: rapid review of the evidence. Lancet, v.395, n.10227, p.912-920, 2020. doi: 10.1016 / S0140-6736 (20) 30460-8.

CASCELLA, M. et al. Features, evaluation and treatment Coronavirus (COVID-19). Treasure Island: StatPearls Publishing, 2020.

CHAN, J.F.W. et. al. A familial cluster of pneumonia associated with the 2019 novel coronavirus indicating person-to-person transmission: a study of a family cluster. Lancet, v.395, n.10223, p.514-523, 2020. doi: 10.1016/S0140-6736(20)30154-9. 
CHANG, M. et al. Epidemiologic and Clinical Characteristics of Novel Coronavirus Infections Involving 13 Patients Outside Wuhan, China. JAMA, v.23, n.11, p.1092-1093, 2020. doi: 10.1001 / jama.2020.1623.

CHEN, Y. et al. A doença renal está associada à morte intrahospitalar de pacientes com COVID-19. Kidney Int., v.97, n.5, p. $829-838 ; 2020$.

COMAS-GARCIA, M. Empacotamento de RNA genômico em vírus de RNA de cadeia única de sentido positivo: uma história complexa. Virus, v.11, n.3, p.253, 2019.

CRODA, J. et al., COVID-19 in Brazil: advantages of a socialized unified health system and preparation to contain cases. J. Braz. Soc. Trop. Med., v.53, p.1-6, 2020. doi: 10.1590/0037-86820167-2020.

DE OLIVEIRA, W. K. et al. Guia de Vigilância Epidemiológica: emergência de saúde pública de importância nacional pela doença pelo Coronavírus 2019. Brasília: MS, 2020.

EBRAHIM et al. COVID-19 in the least developed, fragile, and conflict-affected countries: How can the most vulnerable be protected? Int.nal Journal of Infectious Diseases. Perspective, v.102, p.381-388, 2020. doi: 10.1016/j.ijid.2020.10.055.

GARCIA, L. P. DUARTE, E. Intervenções não farmacológicas para o enfrentamento à epidemia da Covid-19 no Brasil. Epidemiol. Serv Saúde, v.29, n.2, p.e2020222, 2020. doi: 10.5123/ s1679-49742020000200009.

GONÇALVES, E.N. A necessária transição planetária: (in) convenientes do Covid-19 para viabilizar a benfazeja colheita futura no Brasil e na Comunidade Internacional de Estados. Rev. Jurídica, v.2, n.59, p.255-282, 2020. doi:10.21902/ revistajur.2316-753X.v2i59.4091.

GUAN, W. et, al. Clinical characteristics of coronavirus disease 2019 in China. New England J. Med., v382, n.18, p.1708-1720, 2020. doi: 10.1056 / NEJMoa2002032.

HABIBZADEH, P. STONEMAN, E. K. The Novel Coronavirus: a bird's eye view. Int. J. Occup Environ Med., v.11, n.2, p.65-71, 2020. doi: 10.15171/ijoem.2020.1921.

HE, X. et. al. Temporal dynamics in viral shedding and transmissibility of COVID-19. Nat Med. v.26, n.5, p.672675, 2020. doi: 10.1038/s41591-020-0869-5.

HENRIQUE, C.M.P.; VASCONCELOS, W. Crises dentro da crise: respostas, incertezas e desencontros no combate à pandemia da Covid-19 no Brasil. Estud. Av., v.34, n.99, p.25-44, 2020. doi: 10.1590/s0103-4014.2020.3499.003.

HOPKINS, J. University of Medicine. Coronavirus Research Center. 2020. Disponível em: https://coronavirus.jhu.edu/map. html

HUANG et al. Clinical features of patients infected with 2019 novel coronavirus in Wuhan, China. Lancet, v.395, n.10223, p.497-506, 2020. doi: 10.1016/S0140-6736(20)30183-5.

JACOFSKY, D. et al. Understanding Antibody Testing for COVID-19. J Arthroplasty. v.35, n.7, p. S74-S8, 2020. doi: 10.1016/j.arth.2020.04.055.

JIN, Y. et al. Virology, epidemiology, pathogenesis, and Control of COVID-19. Viruses, v.12, n.4, p. 372, 2020. doi: 10.3390/ v12040372.

KAMPF, G. et al. Persistence of coronaviruses on inanimate surfaces and their inactivation with biocidal agents. J. Hosp. Infect., v. S0195-6701, n.20, p.30046-3, 2020.

KUCHARSKI, A. J. et al. Early dynamics of transmission and control of COVID-19: a mathematical modelling study. Lancet
Infect. Dis., v.20, n.5, p.553-558, 2020. doi: 10.1016/S14733099(20)30144-4.

LAI, C. C. Severe acute respiratory syndrome coronavirus 2 (SARS-CoV-2) and coronavirus disease-2019 (COVID-19): The epidemic and the challenges. Int. J. Antimicro.b Agents, v.55, n.3, p.105924, 2020. doi: 10.1016/j.ijantimicag.2020.105924.

LAM, T. T. Y, et al. Identification of 2019-nCoV related coronaviruses in Malayan pangolins in southern China. Bio Rxiv, 2020. doi: 10.1101/2020.02.13.945485.

LEDO, M. E. Clima e estação não são suficientes na contenção da pandemia. Instituto IDOR Pesquisa e Ensino. Rede DIOR São Luiz. Rio de Janeiro. 2020.

LEUNG, et al. First-wave COVID-19 transmissibility and severity in China outside Hubei after control measures, and second-wave scenario planning: a modelling impact assessment. Lancet, v.395, p.1382-1393, 2020. doi: 10.1016/S0140-6736(20)30746-7.

LETKO, M.; MUNSTER, V. Functional assessment of cell entry and receptor use for SARS-CoV-2 and other linhagem B betacoronavírus. Nat. Microbiol., v.5, p.562-569, 2020. doi: 10.1038/s41564-020-0688-y.

Li, Q. et al. Early transmission dynamics in Wuhan, China, of novel coronavirus-infected pneumonia. N. Engl. J. Med., v.382, p.1199-1207. 2020. doi: 10.1056/NEJMoa2001316.

LIU, X. et al. Depression after exposure to stressful events: Lessons learned from the severe acute respiratory syndrome epidemic. Comprehensive Psychiatr., v.53, n.1, p.15-23, 2012. doi: 10.1016/j.comppsych.2011.02.003.

LU, R. et al. Genomic characterisation and epidemiology of 2019 novel coronavirus: implications for virus origins and receptor binding. Lancet, v.395, n.10224, p.565-574, 2020. doi: 10.1016/ S0140-6736(20)30251-8.

LU, H. Opções de tratamento de drogas para o novo coronavírus 2019 (2019-nCoV) Biosci Trends.v.14, n.1, p: 69-71, 2020.

MCINTOSH, K. UpToDate. Coronavirus Disease 2019 (COVID-19). USA: 2020. Disponível em: < https://www. uptodate.com/contents/coronavirus-disease-2019-covid-19. Acesso em: 22 out. 2020.

MOUSAVIZADEH, L.; GHASEMI, S. Genótipo e fenótipo de COVID-19: Seus papéis na patogênese. J. Microbiol Immunol. Infect., n.20, p.30082-30087, 2020. doi: 10.1016/j. jmii.2020.03.022.

NASSIRI, R. Perspective on wuhan viral pneumonia. Advances in public health. Comm. Trop. Med., v.20, n.2, 2020.

OMS, Organização Mundial de Saúde. Discurso de abertura do Diretor-Geral da OMS no briefing para a mídia sobre COVID-19. Organização Mundial da Saúde, 2020a.

OMS, Organização Mundial de Saúde. Relatórios de situação. Disponível em: https://www.who.int/emergencies/diseases/ novel-coronavirus-2019/situation-reports/ Acesso em: 31 maio 2020 .

THOMPSON, R. Pandemic potential of 2019-nCoV. Lancet, v.20, n.3, p.280, 2020. doi:10.1016/S1473-3099(20)30068-2.

PANG, J. et. al. Potencial diagnóstico rápido, vacina e terapêutica para novo coronavírus 2019 (2019-nCoV): Uma revisão sistemática. J. Clin. Med., v.9, p.623, 2020.

PARANJPE, I. et al. Association of treatment dose anticoagulation with in-hospital survival among hospitalized patients with COVID-19. J. Am. Coll. Cardiol., v.76, n.1, p.122-124, 2020. doi: 10.1016/j.jacc.2020.05.001. 
PARMET et. al. Covid-19: the law and limits of quarantine. $N$. Engl. J. Med., v.382, n. e28, 2020. doi: 10.1056/NEJMp2004211.

PERALES et al. Estratégias antivirais baseadas em mutagênese letal e limite de erro. Quasispecies, p.323-339, 2015.

PONDÉ, L.F. O Mundo Pós-Pandemia: amizade e família. Disponível em: https://www.youtube.com/watch? $\mathrm{v}=\mathrm{xF} 1 \mathrm{mPBGb}$ To

PRUIJSSERS, A.J.; DENISON, M.R. Análogos de nucleosídeos para o tratamento de infecções por coronavírus. Curr Opinion Virol. v.35, p.57-62, 2019.

PROMPETCHARA et. al. Immune responses in COVID-19 and potential vaccines: Lessons learned from SARS and MERS epidemiC. Asian Pac. J. Allergy Immunol., v.38, p.1-9, 2020.

QUALLS, N. et al. Community Mitigation Guidelines to Prevent Pandemic Influenza - United States, 2017. MMWR Recomm., v.66, n.1, p.1-34, 2017. doi:10.15585/mmwr.rr6601a1.

RABENAU, H.F. et al. Stability and inactivation of SARS coronavírus. Med. Microbiol. Immunol., v.194, n. 1-2, p.1-6, 2005. doi: 10.1007/s00430-004-0219-0.

REQUIA, W.J. et al. Risk of the Brazilian health care system over 5572 municipalities to exceed health care capacity due to the 2019 novel coronavirus (COVID-19). Scie. Total Environment., v.730, n.15, p. 139-144, 2020. doi:10.1016/j.scitotenv.2020.139144.

RIBOLI, E. et al. No epicentro da epidemia: um olhar sobre a Covid-19 na Itália. Cogitare Enferm., v. 25, 2020. doi: 10.5380/ ce.v25i0.72955.

ROCHA, C. A dificuldade do Brasil para aplicar testículos em massa na pandemia. 2020. Disponível em: https://www. nexojornal.com.br/expresso/2020/04/10/A-dificuldade-doBrasil-de aplicar-testes-em-massa-na-pandemia. Acesso em: 31 maio 2020.

RODRIGUEZ-MORALES, A.J. et al. COVID-19, an Emerging Cornavirus Infection: Current Scenario and Recent Developments - An Overview. J. Pure Appl. Microbiol., v.14, p. 6150, 2020a.

RODRIGUEZ-MORALES et al. COVID-19 in Latin America. The implications of the first confirmed case in Brazil. Travel Med. Infect. Dis., v.35, p.101613, 2020.

ROTHE, C. et al. Transmissão da infecção 2019-nCoV a partir de um contato assintomático na Alemanha. N. Engl. J. Med., 2020. doi: 10.1056/NEJMc2001468.

SENHORAS, E. M. "Coronavírus e Educação: Análise dos Impactos Assimétricos”. Boletim de Conjuntura (BOCA), v.2, n.5, 2020 .

SHANMUGARAJ, B. et al. Emergence of novel coronavirus 2019-nCoV: Need for rapid vacina and biologics development. Pathogens. v.9, p.148, 2020. doi: 10.3390/pathogens9020148.

SILVA, A. et. al. Impactos causados pela COVID-19: um estudo preliminar. Rev. BEA, v.15, n.4, p.128-147, 2020.

SINGH, A.K. et al. A. Cloroquina e hidroxicloroquina no tratamento de COVID-19 com ou sem diabetes: Uma pesquisa sistemática e uma revisão narrativa com uma referência especial à Índia e outros países em desenvolvimento. Diab. Metab. Syndr., v.14, n.3, p. 241-246, 2020.

STORYMAPS. Mapping the novel coronavirus pandemic Esri's Story Maps. Disponível em: https://storymaps.arcgis.com/ stories/4fdc0d03d3a34aa485de1fb0d2650ee0. Acesso em: 31 maio 2020 .

TANG, J. W. et al. Emergence of a novel coronavirus causing respiratory illness from Wuhan, China. J. Infect., v.80, n.3, p.350-

\section{1, 2020. doi: 10.1016/j.jinf.2020.01.014.}

TURCI, M. A. et al. A Vigilância Epidemiológica diante do SarsCov-2: desafios para o Sus e a Atenção Primária à Saúde. APS Rev., v.2, p.44-55, 2020. doi:10.14295/aps.v2i1.70.

UJIKE, M, TAGUCHI, F. Incorporation of spike and membrana glycoproteins into coronavirus virions. Virus.v.7, n.4, p.17001725, 2015. doi: 10.3390/v7041700.

VAN DOREMALEN N, et al. Aerosol and Surface Stability of SARS-CoV-2 as Compared with SARS-CoV-1. N. Engl. J. Med., v.382, n.16, p.1564-1567, 2020. doi: 10.1056/NEJMc2004973.

VELAVAN, T.P.; MEYER, C.G. The COVID-19 epidemic. Trop. Med. Int. Health, v.25, n.3, 2020. doi: 10.1111/tmi.13383.

VILELA, D. A. M. The value of mitigating epidemic peaks of COVID-19 for more effective public health responses. J. Braz. Soc. Trop. Med., v.53, p.e20200135, 2020. doi:10.1590/00378682-0135-2020.

WANG et al. Clinical characteristics of 138 hospitalized patients with 2019 novel coronavirus-infected pneumonia in Wuhan, China. JAMA, v.323, n.11, p.1061-1069, 2020. doi: 10.1001/ jama.2020.1585.2020.

WEISS, S.R.; NAVAS-MARTIN, S. Coronavírus patogênese e o patógeno emergente síndrome respiratória aguda grave coronavírus. Microbiol. Mol. Biol. Rev., v. 69, n.4, p.635664. 2005.

WIT, E. et al. SARS and MERS: SARS and MERS: recent discoveries about emerging coronaviruses. Nat. Rev. Microbiol., v.14, p.523-534, 2016. doi: 10.1038/nrmicro.2016.81.

WHO. Word Health Organization. Report of the WHO-China Joint Mission on Coronavirus Disease 2019 (COVID-19). China: Word Health Organization, 2020.

WHO, Pneumonia de causa desconhecida - China: notícias de surto de doença. Genebra: Organização Mundial da Saúde, 2020 b.

WHO - World Health Organization. Coronavirus disease (COVID-19) advice for the public. 2020. Disponível em: https:// www.who.int/emergencies/diseases/novel-coronavirus-2019/ advice-for-public. Acesso em: 19 out. 2020.

WHO. World Health Organization. Novel coronavirus (2019nCoV). 2020. Disponível em: http:// www.euro.who.int/en/ health-topics/healthemergencies/novel-coronavirus-2019-ncov_ old. Acesso em: 19 out. 2020.

WHO. World Health Organization. Pan Americam Health Organization. Epidemiological Update: Coronavirus disease (COVID-19) - 9. 2020. Disponível em: https://www.paho.org/en/ documents/epidemiological-update-coronavirus-disease-covid19-9-november-2020. Acesso em: 19 out. 2020.

WHO, World Health Organization. WHO Library Cataloguingin-Publication Data Infection prevention and control of epidemicand pandemic-prone acute respiratory infections in health care. Guideline: World Health Organization, 2014.

WILKEN J, et al. A. Knowledge, attitudes, and practices among members of households actively monitored or quarantined to prevent transmission of ebola virus disease-margibi county, liberia: February-march 2015. Prehos. Dis. Med., v.32, n.6, p:673-678, 2017. doi: 10.1017/S1049023X17006720.

YANG, Y. et al. The deadly coronaviruses: the 2003 SARS pandemic and the 2020 novel coronavirus epidemic in China. J Autoimmun., v.109, n.102434, p.1-16, 2020. doi: 10.1016/j. jaut.2020.102434.

ZANG et. al. Origin and evolution of the 2019 novel coronavirus. Clin. Infect. Dis., v.71, n.15, p.882-883, 2020. doi: 10.1093/cid/ 
ciaal12.

ZHU, N. et al. A Novel Coronavirus from patients with pneumonia in China, 2019. N. Engl. J. Med., v.382, n.8, p.727-33, 2020. doi: 10.1056/NEJMoa2001017. 